\title{
Nutritional status of under-five children in rural Bangladesh
}

\author{
Liton Chadra Sen ${ }^{1}$, Md. Sabbir Ahmed ${ }^{2}$, Abu Shoeb Md. Touhiduzzaman ${ }^{3}$, Soumitra Mandal ${ }^{4}$, \\ AH Towfique Ahmed ${ }^{5}$, Sanjit Kumar Das ${ }^{6}$, Rama Saha ${ }^{7}$ \\ ${ }^{1,2,3,4}$ Department of Community Health and Hygiene, Faculty of Nutrition and Food Science, Patuakhali Science and \\ Technology University, Bangladesh \\ ${ }^{5,6,7}$ Barisal Field Office, UNICEF Bangladesh, Bangladesh
}

\begin{tabular}{|c|c|}
\hline Article Info & ABSTRACT \\
\hline Article history: & \multirow{11}{*}{ 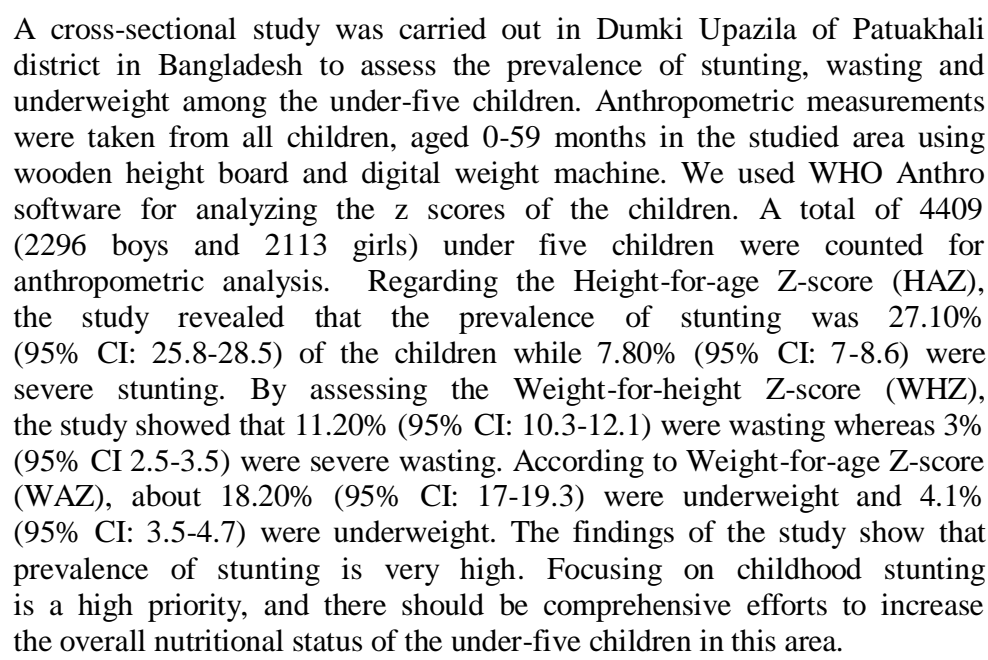 } \\
\hline Received Feb 28, 2020 & \\
\hline Revised May 16, 2020 & \\
\hline Accepted Jun 17, 2020 & \\
\hline Keywords: & \\
\hline Nutritional status & \\
\hline Rural Bangladesh & \\
\hline Malnutrition & \\
\hline Stunting & \\
\hline Under-five children & \\
\hline & \\
\hline
\end{tabular}

This is an open access article under the CC BY-SA license.

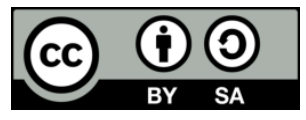

\section{Corresponding Author:}

Md. Sabbir Ahmed,

Department of Community Health and Hygiene,

Patuakhali Science and Technology University,

Dumki, Patuakhali-8602, Bangladesh.

Email: sabbir.nfs@gmail.com

\section{INTRODUCTION}

Nutrition is believed to be very essential for socio-economic development of a country and is an essential component of achieving sustainable development goals. Nutritional status of under-five children in a community is an indicator of the level of development and future prospect of the community [1-2]. The nutritional status of infants and under-five children is a particular concern since the early years of life are critical for optimal growth and development in future [3-4]. Proper nutrition of children leading to adequate growth and good health is the essential foundation of human development [5]. Moreover, high prevalence of malnutrition hamper future economic growth by reducing the intellectual and physical capability of entire population [6].

Malnutrition is one of the important public health problems of developing countries where resources are low and more common the under-five children [7-9]. The common causes of malnutrition among the under-five children is lack of access to the nutritious food. Additionally, poor feeding practices, respiratory infections, frequent diarrhea and malaria also identified as an underline causes of malnutrition 
among this age group. Worldwide, over 10 million children under the age of 5 years are dying every year from preventable and treatable illnesses in spite of effective health interventions [10]. Among the deaths more than one-third of deaths are caused by malnutrition [11]. Globally, 165 million children under 5 years of age were stunted, 101 million children were underweight and 52 million children were wasted [12]. Sub-Saharan Africa and South Asia are home to three fourths of the world's stunted children. In South Asia, 39 per cent of children under 5 years of age were stunted. The prevalence of underweight and wasting is alarmingly high in South Asia where 33\% are underweight and $16 \%$ are wasted i.e approximately 1 in 3 children is underweight and 1 in 6 children is wasted. These children are at increased risk of severe acute malnutrition and death [13]. Bangladesh is a developing country experiencing burden of higher percentages of childhood malnutrition. A recent study revealed that in Bangladesh, among under-five children $43 \%$ were stunted (chronic malnutrition), $17 \%$ were wasted (acute malnutrition) and $41 \%$ were underweight (under nutrition) [14].

Improved nutrition and health enhance the learning ability of children [15]. In the long run it leads to an increase in the strength of the labor force and thereby it contributes positively to the economic growth and a good nutrition is essential for healthy, thriving individuals, families and a nation [16-17]. Moreover, the nutritional status of children is a manifestation of a host factors, including household access to food and the distribution of this food within the household, availability and utilization of health services, and the care provided to the child [18]. Therefore, the objective of this study was to assess the prevalence of stunting, wasting and underweight among the under-five children in a rural area of Bangladesh.

\section{RESEARCH METHOD}

This cross-sectional study was carried out in Dumki upazila of Patuakhali district in Bangladesh. Anthropometric data were collected through the Nutrition Internship Program for the undergraduate students of Nutrition and Food Science studying in Patuakhali Science and Technology University which was supported by UNICEF Bangladesh. All the data were collected through the three phases of the internship program. Data were collected during October 2016-December 2016 (1st phase), November 2017-January 2018 (2nd phase) and March 2019-May 2019 (3rd phase). A two days long intensive training program was conducted to prepare the intern students before data collection to adhere them with the data collection tools and techniques (including anthropometric measurements). At first a household database was prepared by surveying the studied area. For the anthropometric measurements we have considered children aged from 0-59 months because surveying this age group provide an indication of the severity of under-nutrition among all people living in a geographical area under similar conditions [9]. From the household data base we filtered the households with at least one child aged 0-59 months for inclusion in the survey. Trained interns then visited all the selected households. If no one was in the house during the visit, two repeat visits were made to include all the eligible households for the study. Our study covered all the children in this age group permanently residing in the studied area. Participants' enrollment procedure for this study is described in the flow chart as shown in Figure 1.

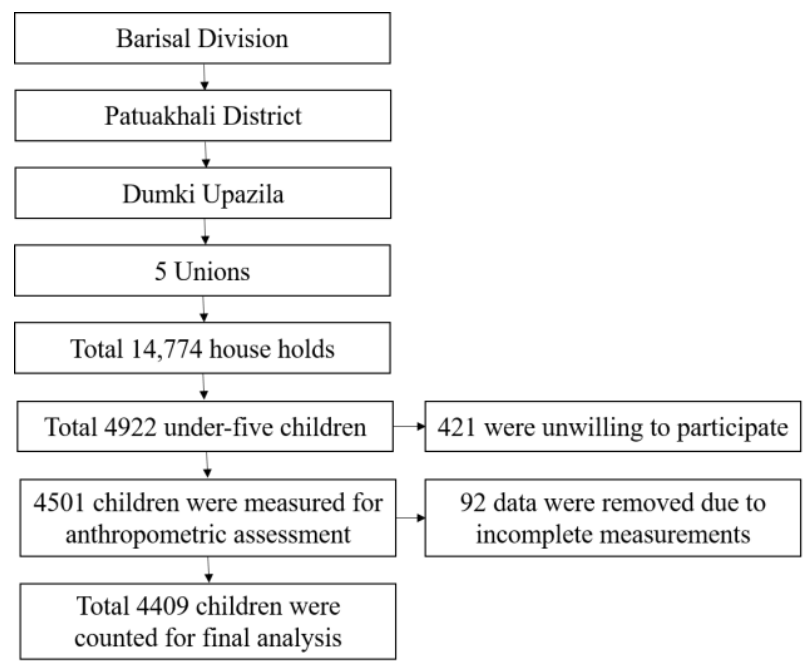

Figure 1. Participant's enrollment procedure for this study 
Anthropometric measurements were taken from all children, aged 0-59 months in this cross sectional survey to assess their nutritional status. Wooden height board was used to measure the height/length of the children and readings were taken to the nearest centimeter. Portable digital (Camry, Model: EB9062) weight scales were used to measure the weight of the children with light cloths and bare foot. The scales were checked for accuracy and calibrated every day before data collection. Weights were recorded to the nearest $0.1 \mathrm{~kg}$. Children were unable to stand, were weighed with their mothers, then the weight of the mothers was measured alone, and the weight of the children was noted from the difference of two weights.

\subsection{Analysis of data}

Anthropometric indices were calculated using reference medians recommended by the world health organization (WHO) and classified according to standard deviation units (z-scores), based on the WHO criteria [19] Wasting (weight-for-height z-score-WHZ) indicates thinness. It is usually the result of recent nutritional deficiency and is affected by seasonal shifts associated with availability of foods and/or prevalence of disease. A WHZ of <-2 defines the presence of acute malnutrition (wasting). Stunting, represented by low height-for-age z-score (HAZ), results from extended periods of inadequate food intake, poor dietary quality, increased morbidity, or a combination of these factors. A HAZ of <-2 defines chronic malnutrition (stunting). Weight for- age z-score (WAZ) is essentially a composite of weight-for-height and height-for-age, thus a measure of both acute and chronic malnutrition. A WAZ of $<-2$ is used for defining a child as underweight. A z-score of <-3 defines severe levels of each of the indices. WHO Anthro software [20] was used for analyzing the nutritional status of the children. Bivariate analysis was used to assess the mean differences of the z-scores among the gender and age group by using IBM SPSS software (v.23) and Microsoft word (2013) was used for tabular and graphical representation of the data.

\subsection{Ethical considerations}

Informed consent was obtained from the parents (father/mother) of the children. All procedures performed in this study involving human participants were in accordance with the ethical standard of institutional ethical committee (IEC) of the University and with the 1975 Helsinki Declaration.

\section{RESULTS AND DISCUSSION}

A total of 4409 (2296 boys and 2113 girls) under five children were counted for anthropometric analysis. Regarding the Height-for-age Z-score (HAZ), the study revealed that the prevalence of stunting was $27.10 \%$ (95\% CI: 25.8-28.5) of the children while $7.80 \%$ (95\% CI: 7-8.6) were severe stunting. By assessing the Weight-for-height Z-score (WHZ), the study showed that $11.20 \%$ (95\% CI: 10.3-12.1) were wasting whereas, 3\% (95\% CI 2.5-3.5) were severe wasting. According to Weight-for-age Z-score (WAZ), about $18.20 \%$ (95\% CI: 17-19.3) were underweight and 4.1\% (95\% CI: 3.5- 4.7) were underweight Figure 2.

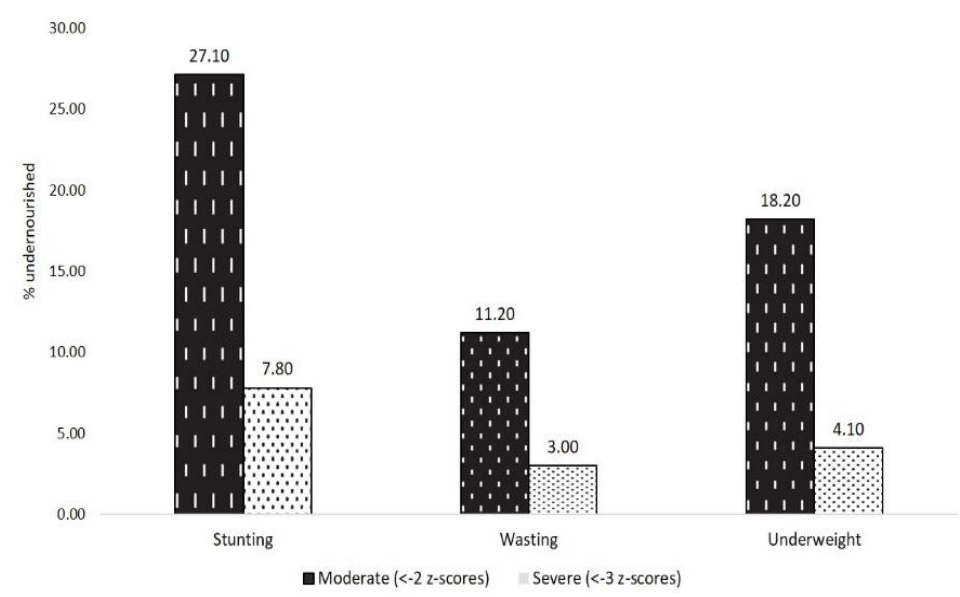

Figure 2. Prevalence of severe and acute malnutrition among under-five children

Both moderate and severe stunting was most prevalent among the children aged 6-47 months. Similar proportions $(36.1 \%)$ of males were stunted as females $(33.6 \%)$. The prevalence of wasting was common among the children aged 24-60 months. Though, wasting was highest among the children aged 0-5 months. The proportion of girls wasting (13.5\%) was similar to boys wasting (14.8\%). The prevalence 
of moderate underweight children was the highest (22.3\%) among children aged 36-47 months; however severe underweight $(4.8 \%)$ peaked in children aged 6-11 months. The moderate underweight was seen to increase with advancing age of the children, but downward among the children aged 48-60 months. It was observed that male (21.8\%) were more underweight as compared to female (13.5\%) as presented in Table 1.

Table 1. Nutritional status of the children for different age group

\begin{tabular}{|c|c|c|c|c|c|}
\hline Anthropometric measurements & $\mathrm{N}$ & $\%<-3 \mathrm{SD}$ & $95 \% \mathrm{CI}$ & $\%<-2 \mathrm{SD}$ & $95 \% \mathrm{CI}$ \\
\hline \multicolumn{6}{|l|}{ Length/height-for-age (Stunting) } \\
\hline \multicolumn{6}{|l|}{ Age (months) } \\
\hline $0-5$ & 126 & 5.6 & $1.2-10$ & 20.6 & $13.2-28.1$ \\
\hline $6-11$ & 458 & 8.5 & $5.8-11.2$ & 26 & $21.9-30.1$ \\
\hline $12-23$ & 844 & 8.9 & $6.9-10.9$ & 29.1 & $26-32.3$ \\
\hline $24-35$ & 909 & 8.5 & $6.6-10.3$ & 29.5 & $26.5-32.5$ \\
\hline $36-47$ & 794 & 8.3 & $6.3-10.3$ & 29.2 & $26-32.4$ \\
\hline $48-60$ & 1278 & 6.3 & $4.9-7.6$ & 23.9 & $21.6-26.3$ \\
\hline \multicolumn{6}{|l|}{ Gender } \\
\hline Boys & 2296 & 8.6 & $7.5-9.8$ & 27.5 & $25.7-29.4$ \\
\hline Girls & 2113 & 6.9 & $5.8-8$ & 26.7 & $24.8-28.7$ \\
\hline Total & 4409 & 7.8 & 7-8.6 & 27.1 & 25.8-28.5 \\
\hline \multicolumn{6}{|c|}{ Weight-for-length/height (Wasting) } \\
\hline \multicolumn{6}{|c|}{ Age (months) } \\
\hline $0-5$ & 126 & 4.8 & $0.6-8.9$ & 14.3 & $7.8-20.8$ \\
\hline $6-11$ & 458 & 3.7 & $1.9-5.6$ & 9.6 & $6.8-12.4$ \\
\hline $12-23$ & 844 & 2.3 & $1.2-3.3$ & 9.4 & $7.3-11.4$ \\
\hline $24-35$ & 909 & 3.2 & $2-4.4$ & 11.2 & $9.1-13.3$ \\
\hline $36-47$ & 794 & 3.1 & $1.9-4.4$ & 12.8 & $10.5-15.2$ \\
\hline $48-60$ & 1278 & 2.8 & $1.9-3.8$ & 11.7 & $9.9-13.5$ \\
\hline \multicolumn{6}{|l|}{ Gender } \\
\hline Boys & 2296 & 3.1 & $2.4-3.8$ & 11.7 & $10.4-13.1$ \\
\hline Girls & 2113 & 2.9 & $2.1-3.6$ & 10.6 & $9.3-12$ \\
\hline Total & 4409 & 3 & 2.5-3.5 & 11.2 & 10.3-12.1 \\
\hline \multicolumn{6}{|l|}{ Weight-for-age (Underweight) } \\
\hline \multicolumn{6}{|l|}{ Age (months) } \\
\hline $0-5$ & 126 & 4 & $0.2-7.8$ & 13.5 & $7.1-19.9$ \\
\hline $6-11$ & 458 & 4.8 & $2.7-6.9$ & 14.4 & $11.1-17.7$ \\
\hline $12-23$ & 844 & 3 & $1.8-4.2$ & 14.3 & $11.9-16.8$ \\
\hline $24-35$ & 909 & 4.3 & $2.9-5.7$ & 18.7 & $16.1-21.3$ \\
\hline $36-47$ & 794 & 4.7 & $3.1-6.2$ & 22.3 & $19.3-25.3$ \\
\hline $48-60$ & 1278 & 4.2 & $3.1-5.4$ & 19.6 & $17.3-21.8$ \\
\hline \multicolumn{6}{|l|}{ Gender } \\
\hline Boys & 2296 & 3.7 & $2.9-4.5$ & 18.1 & $16.5-19.7$ \\
\hline Girls & 2113 & 2.9 & $2.1-3.6$ & 10.6 & $9.3-12$ \\
\hline Total & 4409 & 4.1 & $3.5-4.7$ & 18.2 & 17-19.3 \\
\hline
\end{tabular}

In our present study we found a higher prevalence of stunting, wasting and underweight among the under-five children in the studied area. About 5.5 million children under 5 years $(36 \%)$ were suffering from chronic malnutrition (stunting or low height-for-age), 33\% underweight (low weight-for-age), and $14 \%$ acutely malnourished (wasting or low weight-for-height) [21]. According to MICS 2014 report in Bangladesh, the prevalence of malnutrition in under-5 children were $9.6 \%$ wasting ( $1.6 \%$ severe wasting), $31.9 \%$ underweight ( $8.8 \%$ severely underweight), 36\% stunting (12\% severely stunted). The present study showed higher wasting but lower stunting and underweight as compared to national prevalence [22]. Here, the prevalence of underweight was almost two times lower than the national prevalence of Bangladesh [22]. But it was very nearly similar to one of study in rural Nepal [13]. In Barishal, underweight prevalence was higher, stunting prevalence two times lower than the present study whereas wasting was similar [22]. The prevalence of acute malnutrition of the study was lower as compared to Hoque et al. and Mamulwar et al. [23, 24]. The prevalence of acute malnutrition of West Nalua, a neighboring village of Dumki Upazila was higher than the study area [25]. Stunting prevalence of Bangladesh was high among the children aged 6-47 months which was same as present study. Prevalence of stunting among the boys and girls were similar proportion both national and study area. Regarding the MICS 2014 report, wasting was most prevalent at the age group 12-23 months while the prevalence of wasting highest at 0-5 month's group. The proportion of girls wasting was lower than boys wasting but the present study showed similar prevalence. Severe underweight was peaked in children aged 6-11 months in the study area, however it was high at the aged 24-36 months 
in Bangladesh. The proportion of severe and moderately underweight children was seen to increase with advancing age of the child, but downward among the children aged 36-60 months [24]. The prevalence of underweight was similarly upturned with the advancing age of the child, but descending among the children aged 48-60 months. According to MICS 2014 report males and females underweight prevalence at the same, while males were more as compared to female in the study.

\section{CONCLUSION}

In conclusion, the result of this study has revealed the existence of high prevalence of malnutrition, especially stunting among under-five children in this study area. Policy makers should be concerned about the high prevalence of severe and moderate malnutrition and its recent increasing trends. This knowledge can be used to assess the function of running child development programs and plan for future interventions to improve the overall nutritional status of the children.

\section{ACKNOWLEDGEMENTS}

The authors would like to acknowledge UNICEF Bangladesh for their financial and logistic support during the internship program; the authors also thank all the intern students of the faculty of Nutrition and Food Science.

\section{REFERENCES}

[1] Q. D. Badake et al., "Nutritional status of children under five years and associated factors in Mbeere South District, Kenya," African Crop Science Journal, vol. 22, no. S4, pp. 799-806, 2014.

[2] N. Sakwe et al., "Relationship between malaria, anemia, nutritional and socio-economic status amongst under-ten children, in the North Region of Cameroon: A cross-sectional assessment," PLoS One, vol. 14, no. 6, 2019.

[3] S. J. Schwarzenberg and M. K. Georgieff, "Advocacy for improving nutrition in the first 1000 days to support childhood development and adult health," Pediatrics, vol. 141, no. 2, 2018.

[4] H. Piechulek, J. M. Aldana, and M. N. Hasan, "Feeding practices and malnutrition in children in rural Bangladesh," Food and Nutrition Bulletin, vol. 20, no. 4, pp. 395-400, 1999.

[5] D. Kumar, N. K. Goel, P. C. Mittal, and P. Misra, "Influence of infant-feeding practices on nutritional status of under-five children.," The Indian Journal of Pediatrics, vol. 73, no. 5, pp. 417-421, 2006.

[6] J. Kabubo-Mariara, G. K. Ndenge, and D. K. Mwabu, "Determinants of children's nutritional status in Kenya: Evidence from Demographic and Health Surveys," Journal of African Economies, vol. 18, no. 3, pp. 363-387, 2009.

[7] S. S. Masood-us-Syed, S. Muhammd, and Z. K. Butt, "Nutritional assessment of children under the age of sixty months in district Sialkot, Pakistan," Journal of Pioneering Medical Students, vol. 1, no. 1, 2011.

[8] T. R. Bhandari and M. Chhetri, "Nutritional status of under five year children and factors associated in Kapilvastu District, Nepal," Journal of Nutritional Health and Food Science, vol. 1, no. 1, pp. 1-6, 2013.

[9] B. Olack et al., "Nutritional status of under-five children living in an informal urban settlement in Nairobi, Kenya," Journal of Health, Population and Nutrition, vol. 29, no. 4, pp. 357-363, 2011.

[10] M. Alemayehu, F. Tinsae, K. Haileslassie, O. Seid, G. Gebregziabher, and H. Yebyo, "Undernutrition status and associated factors in under-5 children, in Tigray, Northern Ethiopia," Nutrition, vol. 31, no. 7-8, pp. 964-970, 2015.

[11] UNICEF, “United Nations Children's Fund, The state of the world's children," UNICEF-NY 10017, 2006.

[12] D. Amare, A. Negesse, B. Tsegaye, B. Assefa, and B. Ayenie, "Prevalence of undernutrition and its associated factors among children below five years of age in Bure Town, West Gojjam Zone, Amhara National Regional State, Northwest Ethiopia," Advances in Public Health, vol. 2016, p. 8, 2016.

[13] J. Chataut and K. Khanal, "Assessment of nutritional status of children under five years of age in rural Nepal," Kathmandu University Medical Journal, vol. 53, no. 1, pp. 73-77, 2016.

[14] J. Alom, M. A. Quddus, and M. A. Islam, "Nutritional status of under-five children in Bangladesh: A multilevel analysis," Journal of Biosocial Science, vol. 44, no. 5, pp. 525-535, 2012.

[15] J. R. Behrman, "The impact of health and nutrition on education," The World Bank Research Observer, vol. 11, no. 1, pp. 23-37, 1996.

[16] R. W. Fogel, "Health, nutrition, and economic growth," Economic Development and Cultural Change, vol. 52, no. 3, pp. 643-658, 2004.

[17] D. Danbe Debeko, "Nutritional Status of Under-five Children in Hawassa Zuria District, Southern Ethiopia," American Journal of Health Research, vol. 3, no. 5, pp. 286-292, 2015.

[18] L. J. Christiaensen and H. Alderman, "Child Malnutrition in Ethiopia: Can Maternal Knowledge Augment the Role of Income? Child Malnutrition in Ethiopia: Can Maternal Knowledge Augment The Role of Income?” 2001. [Online]. Available: http://www.worldbank.org/afr/wps/index.htm. 
[19] W. H. Organization, "WHO child growth standards: length/height-for-age, weight-for-age, weight-for-length, weight-for-height and body mass index-for-age: methods and development," 2006. [Online]. Available: https://www.who.int/childgrowth/publications/en/.

[20] W. H. Organization, "Anthro for personal computers, version 3.2. 2, 2011: Software for assessing growth and development of the world's children. Geneva: WHO, 2010.” 2012. [Online]. Available: https://www.who.int/childgrowth/software/anthro_pc_manual_v322.pdf?ua=1.

[21] M. Niport, "Bangladesh demographic and health survey BDHS 2014: key indicators," National Institute of Population Research Training (NIPORT), 2015.

[22] P. Pathey, "Bangladesh multiple indicator cluster survey 2012-2013 Key findings," Bangladesh Bureau of Statistic UNICEF Bangladesh, 2014.

[23] M. A. Hoque, M. A. Sayeed, M. R. Ahsan, M. A. Al Mamun, and F. Salim, "Nutritional Status among under-5 Children of a selected slum in Dhaka city," Northern International Medical College Journal, vol. 7, no. 2, pp. 143-145, 2016.

[24] M. S. Mamulwar et al., "Nutritional status of under-five children in urban slums of Pune," International Journal of Medicine and Public Health, vol. 4, no. 3, pp. 247-252, 2014.

[25] A. S. M. Touhiduzzaman, et al., "Study the Food Habit and Nutritional Status of Mothers and Its Relation to Their Under-5 Child Health at Coastal Region (West Nalua)," International Journal of Health Sciences and Research, vol. 8, no. 4, pp. 175-184, 2018. 